\title{
Parathyroid Hormone-Like Hormone Induces Epithelial-to-Mesenchymal Transition of Intestinal Epithelial Cells by Activating the Runt-Related Transcription Factor 2
}

\author{
Shuying $\mathrm{He},{ }^{*}$ Minmin Xue, ${ }^{\dagger}$ Cuiping Liu, ${ }^{\ddagger}$ Fang Xie, ${ }^{*}$ and Lan Bai*
}

\begin{abstract}
From the Guangdong Provincial Key Laboratory of Gastroenterology, * Department of Gastroenterology, Nanfang Hospital, and the Department of Critical Care Medicine, ${ }^{\ddagger}$ Zhujiang Hospital, Southern Medical University, Guangzhou; and the Department of Gastroenterology, ${ }^{\dagger}$ Chinese People’s Liberation Army 254 Hospital, Tianjin, China
\end{abstract}

Accepted for publication March 6, 2018.

Address correspondence to Lan Bai, Ph.D., Department of Gastroenterology, Nanfang Hospital, 1838 N Guangzhou Ave, Guangzhou, Guangdong 510515, China. E-mail: hsy212@smu.edu.cn.

\begin{abstract}
Epithelial-to-mesenchymal transition (EMT) is a key contributor to fibroblast activation in fibrosis of multiple organs, including the intestine. Parathyroid hormone-like hormone (PTHLH) is an important factor in renal fibrosis and regulates several processes, including EMT. Herein, we investigated the role of PTHLH-induced EMT in intestinal fibrosis associated with Crohn disease. The expression levels of the EMT-related proteins, PTHLH, and parathyroid hormone receptor 1 (PTH1R) in intestinal tissues were determined by immunohistochemistry, and our results revealed that PTHLH and PTH1R were significantly elevated and associated with EMT marker expression. Moreover, neutralizing PTH1R and antagonizing PTHLH bioactivity prevented transforming growth factor- $\beta 1$-induced EMT. PTH1R can propagate the protein kinase $A$ (PKA) signal and activate downstream nuclear transcription factors, including runt-related transcription factor 2 (Runx2). In addition, lentiviral vector-PTHLH-treated mice were highly sensitive to 2,4,6-trinitrobenzene sulfonic acid, and analysis of the PTHLH-PTH1R axis revealed the involvement of PKARunx2 in PTHLH-induced EMT. Our results indicate that PTHLH triggered EMT in intestinal epithelial cells through the PKA-Runx2 pathway, which might serve as a therapeutic target for intestinal fibrosis in Crohn disease. (Am J Pathol 2018, 188: 1374-1388; https://doi.org/10.1016/j.ajpath.2018.03.003)
\end{abstract}

Crohn disease (CD) is a life-long disease, characterized by recurrent episodes of inflammation, followed by mucosal healing, that cause mucosal and submucosal deposition of extracellular matrix (ECM), which progressively leads to intestinal fibrosis and eventually stricture formation. ${ }^{1-6}$ To relieve obstruction related to fibrotic strictures, $>80 \%$ of patients require at least one surgery during the course of their disease., ${ }^{4,8}$ Myofibroblasts are the major source of ECM, similar to fibrosis in other organs. ${ }^{9}$ However, the origin of the myofibroblasts is unclear. Therefore, a better understanding of the origin of myofibroblasts may provide opportunities to develop new therapeutic approaches.

Epithelial-to-mesenchymal transition (EMT) is a biological process in which epithelial cells lose their phenotypic and functional characteristics and assume a mesenchymal cell phenotype, which includes enhanced migratory and invasive behavior and greatly increased production of ECM components. ${ }^{10-12}$ Through this process, epithelial cells became a key contributor to the pool of activated fibroblasts in multiple organ systems. ${ }^{12-16}$ Accumulating evidence has demonstrated that EMT is an essential part of the pathogenesis of CD-associated intestinal fibrosis and fistulas. ${ }^{17-21}$ In an animal model of intestinal fibrosis induced by 2,4,6trinitrobenzene sulfonic acid (TNBS), fibroblast-specific protein $1(\mathrm{FSP} 1)^{+}$cells of intestinal epithelial origin were detected. ${ }^{21}$ Accumulated data suggest that EMT is essential for the

Supported by National Natural Science Foundation of China grant 81470790 (L.B.), Natural Science Foundation of Guangdong Province grant 2015A030313295 (L.B.), and the Guangzhou Pilot Project of Clinical and Translational Research Center (number 7415696196402).

Disclosures: None declared. 
Table 1 Clinical Features of the CD Patients

\begin{tabular}{ll}
\hline Characteristics & $\begin{array}{l}\text { Values for } \\
\text { CD patients }(n=31)\end{array}$ \\
\hline Female/male ratio (\%) & $24: 7(77: 23)$ \\
Age, years & $26.94 \pm 9.52$ \\
CDAI, $n(\%)$ & \\
$\quad$ Active stage & $28(90)$ \\
$\quad$ Remissive & $3(10)$ \\
Location during disease course, $n(\%)$ & \\
Ileal & $27(87)$ \\
Colonic & $20(65)$ \\
Upper & $15(48)$ \\
Alb, g/L & $33.13 \pm 5.85$ \\
CRP, mg/L & $40.26 \pm 33.78$ \\
Medication, $n$ (\%) & \\
Mesalamine & $8(26)$ \\
Glucocorticoids & $3(10)$ \\
Immunomodulators & $3(10)$ \\
Infliximab & $4(13)$ \\
\hline
\end{tabular}

Data are expressed as means \pm SEM unless otherwise indicated.

Alb, albumin; CD, Crohn disease; CDAI, Crohn's Disease Activity Index; CRP, C-reactive protein.

pathogenesis of CD-associated intestinal fibrosis. ${ }^{18,19,21,22}$ These results indicate that EMT induction in intestinal epithelial cells is likely a centrally important mechanism in the progression of intestinal fibrosis. However, why and how this occurs is currently unclear, and elucidation of the phenomena and molecular mechanisms may provide effective therapeutic interventions for intestinal fibrosis.

The most powerful EMT mediator is transforming growth factor- $\beta$ (TGF- $\beta$ ) ${ }^{10,21}$ Blocking TGF- $\beta 1$ bioavailability or its signaling activity has been shown to dramatically ameliorate liver fibrosis in experimental animals. ${ }^{23,24}$ Parathyroid hormone-like hormone (PTHLH; alias parathyroid hormone-related protein) is a multifunctional peptide that affects cell growth and differentiation and modulates ECM formation via EMT induction. Furthermore, PTHLH is the primary mediator of TGF- $\beta$ in tumor cells and keratinocytes. ${ }^{25-29}$ Earlier findings have shown that PTHLH is widely distributed in many tissues, including intestinal epithelial tissues. ${ }^{29-31}$ PTHLH can be cleaved into several fragments, including an N-terminal PTHLH (1 to 36) fragment, which shares homology with parathyroid hormone $(\mathrm{PTH})$ and is referred to as the common ligand of the PTH/PTHLH type 1 receptor (PTH1R). PTH1R signals are usually coupled with the $\mathrm{G} \alpha \mathrm{S}$-adenylyl cyclase-cAMP-protein kinase A (PKA) intracellular signaling pathway. ${ }^{32}$ Recently, accumulation of PTHLH has been found to promote fibrosis formation. ${ }^{33-36} \mathrm{In}$ damaged kidney, the PTHLH interaction with PTH1R protects tubulointerstitial cells from apoptosis via activation of runtrelated transcription factor 2 (Runx2) and acts as a proinflammatory and profibrogenic factor. ${ }^{37,38}$ However, PTHLH was shown to promote renal fibrosis through EMT. ${ }^{35}$ PTHLH has also been associated with fibrosis and chronic inflammation in chronic pancreatitis. ${ }^{33,39-41}$ PTHLH (1 to 36) activates hepatic stellate cells and promotes ECM deposition. ${ }^{36}$ Previous studies have demonstrated that PTHLH plays an important role in the apoptosis or death of intestinal epithelial cells. ${ }^{42,43}$ These observations led us to investigate whether the PTHLH/PTH1R system is also required for intestinal fibrosis.

Herein, we assessed PTHLH deposition in fibrotic lesions from CD patients and found that PTHLH and PTH1R deposition was positively associated with fibrotic degree and correlated with changes in EMT marker expression in CD. More important, it was found that PTHLH is an important mediator of TGF- $\beta 1$, aggravated the EMT program in intestinal epithelial cells in vitro and in vivo, and activated PTH1R and its downstream signaling pathway to promote intestinal epithelial cell transition into fibroblasts.

\section{Materials and Methods}

\section{Human Tissues}

Thirty-one patients with CD (male/female ratio, 7:24; median age at diagnosis, 26.94 years) were included in the study. All patients underwent a colonoscopy at the Nanfang Hospital of Southern Medical University (Guangzhou, China) from 2014 to 2017. The clinical features of the patients are shown in Table 1. Normal colon tissues were obtained from 17 control patients (male/female ratio, 4:13; median age at colonoscopy, 27.04 years), who underwent diagnostic colonoscopy for reasons other than inflammatory bowel disease, and the examination and histology were found to be normal. CD patients and control patients were matched for age and sex, as well as for other relevant parameters (including the site of tissue sampling). All procedures followed the ethical principles of the World Medical Association Declaration of Helsinki, and the study was approved by the Medical Ethical Committee of Nanfang Hospital.

\section{Reagents}

Recombinant PTHLH (1 to 40) and PTHLH (7 to 34) proteins were purchased from Bachem (Bubendorf, Switzerland), and TGF- $\beta 1$ was purchased from Peprotech (Rocky Hill, NJ). The membrane permeant selective activator of PKA (N6benzoyladenosine- $3^{\prime}, 5^{\prime}$-cyclic monophosphate; $100 \mu \mathrm{mol} /$ L) and the PKA-selective pharmacological inhibitor KT5720 (200 $\mu \mathrm{mol} / \mathrm{L})$ were purchased from Tocris Bioscience (Bristol, UK). ${ }^{44-47}$ TNBS was purchased from SigmaAldrich (St. Louis, MO).

\section{Cell Culture}

The rat intestinal epithelial cell line (IEC-6), human HT-29 cell line, and human osteoblast-like cell line MG-63 were purchased from the Type Culture Collection of the Chinese Academy of Sciences (Shanghai, China). The cells were grown in Dulbecco's modified Eagle's medium containing 
Table 2 Sequences of Specific Primer Pairs

\begin{tabular}{ll}
\hline Primers & Sequence \\
\hline Rattus norvegicus & F: 5'-CACAAGTGCGGTGCAAACTT-3' \\
Runx2 I & R: 5'-AATGACTCGGTTGTTCTCGG-3' \\
Rattus norvegicus & F: 5'-GCTGTTGTGATGCGTATTCCC-3' \\
Runx2 II & R: 5'-CCATGGTGCGGTTGTCGT-3' \\
Homo sapiens & F: 5'-ATGCGTATTGTACCGAGC-3' \\
RUNX2 I & R: 5'-GGTGGTCCGCGATCT-3' \\
Homo sapiens & F: 5'-GAGGGCACAAGTTCTATCTG-3' \\
RUNX2 II & R: 5'-GGTGGTCCGCGATGATCT-3' \\
Mus musculus & F: 5'-CGGACGAGGCAAGAGTTTCA-3' \\
Runx2 I & R: 5'-GGACCGTCCACTGTCACTTTA-3' \\
Rattus norvegicus & F: 5'-GGCACAGTCAAGGCTGAGAATG-3' \\
Gapdh & R: 5'-ATGGTGGTGAAGACGCCAGTA-3' \\
Homo sapiens & F: 5'-TGCACCACCAACTGCTTAGC-3' \\
GAPDH & R: 5'-GGCATGGACTGTGGTCATGAG-3' \\
Mus musculus & F: 5'-ATTGTCAGCAATGCATCCTG-3' \\
Gapdh & R: 5'-ATGGACTGTGGTCATGAGCC-3' \\
\hline
\end{tabular}

$F$, forward; $R$, reverse.

$10 \%$ fetal bovine serum. Cells were maintained at $37^{\circ} \mathrm{C}$ in a $5 \% \mathrm{CO}_{2}$ atmosphere.

\section{PTHLH Lentivirus}

The LV5-EF-1a-GFP+Puro vector that expresses Mus musculus PTHLH (https://www.ncbi.nlm.nih.gov/gene; accession number NM_008970, last accessed February 4, 2018) was purchased from GenePharma (Suzhou, China), and it encoded the full-length peptide.

\section{Animals and Treatment}

BALB/C male mice (6 to 8 weeks old) were obtained from and housed in the Southern Medical University Animal Experiment Center (Guangzhou, China), and the experimental procedures were approved by the Animal Ethics Committee of Nanfang Hospital. The body weight of the mice was within the range of 18 to $20 \mathrm{~g}$, and the TNBS dose was administered independently of weight. ${ }^{21,48}$ Mice were anesthetized by sevoflurane and then administered TNBS/ $45 \%$ ethanol or $45 \%$ ethanol/phosphate-buffered saline (PBS) via a 3.5-F catheter equipped with a $1-\mathrm{mL}$ syringe, which was inserted into the colon until the tip was $4 \mathrm{~cm}$ proximal to the anal verge, and $100 \mu \mathrm{L}$ of TNBS was infused. All mice were randomly divided into four groups (45\% ethanol/PBS group, $n=5 ; n=10$ in other groups). Briefly, mice were divided into an ethanol control group and groups that received TNBS alone or TNBS with either not targeting lentiviral vector (LV-NC) or LV-PTHLH (a total of $1 \times 10^{8}$ lentivirus particles in $100 \mu \mathrm{L}$ of PBS were administered per mouse via weekly i.p. injections performed 48 hours before TNBS enema administration). Intestinal fibrosis was induced by TNBS enema administered at an initial dose of $1 \mathrm{mg} / 0.1 \mathrm{~mL}$ TNBS in $45 \%$ ethanol for the first 2 weeks; the dose was increased to $1.5 \mathrm{mg} / 0.1 \mathrm{~mL}$
TNBS for the third and fourth weeks and increased again to $2 \mathrm{mg} / 0.1 \mathrm{~mL}$ TNBS for weeks 5 to 7 , whereas the control mice received $0.1 \mathrm{~mL}$ of $45 \%$ ethanol alone (vehicle). ${ }^{21,48,49}$ Treatment was performed every 7 days for a total of 7 weeks. Animals were monitored daily for survival throughout the experiment, and 50\% survival was observed in the three TNBS-treated groups. At 7 weeks after administration, the mice were euthanized, and their colons were collected for various analyses.

\section{Histologic Assessment of Intestinal Fibrosis and Inflammation}

Tissue samples were fixed in formalin, embedded in paraffin, cut into sections ( $5 \mu \mathrm{m}$ thick), and stained with both Masson's trichrome stain (Richard-Allan Scientific, Kalamazoo, MI) and hematoxylin and eosin, according to the manufacturer's protocols. The staining was examined with an Olympus IX73 microscope (Olympus, Tokyo, Japan). The scoring system used to assess the histologic damage in TNBS-induced colitis has been previously described. ${ }^{50,51}$ Two gastrointestinal pathologists with special expertise in intestinal inflammation examined each slide in a blinded manner.

\section{Knockdown of Runx2 by RNA Interference}

siRNA was purchased from GenePharma (Suzhou, China). The sequence specifically targeting human Runx2 was $5^{\prime}$ CAGGCGUAUUUCAGAUGAUTT- $3^{\prime}$; the sequence specifically targeting rat Runx 2 was $5^{\prime}$-CCGGGAAUGAGAACUATT- ${ }^{\prime}$; and the negative control sequence was $5^{\prime}$ UUCUCCGAACGUGUCACGUTT- $3^{\prime}$. For transfection, cells were plated at $1 \times 10^{5}$ cells/well in 6-well plates. Cells were transfected with Runx2 siRNA using Lipofectamine 3000 (Invitrogen, Carlsbad, CA). Transfection efficiency and the expression of target proteins were assayed by immunoblotting 48 hours after transfection.

\section{Western Blot Analysis}

Cell and tissue lysates were prepared using radioimmunoprecipitation assay lysis buffer containing $1 \times$ protease cocktail inhibitor, according to general protocols. ${ }^{22}$ The primary antibodies used were as follows: anti-PTHLH (catalog number sc-20728; Santa Cruz Biotechnology, Dallas, TX); anti-PTH1R (catalog number ab75150), anti-vimentin (catalog number ab92547), anti-FSP1 (catalog number ab27957), and anti-collagen I (catalog number ab34710), all obtained from Abcam (Cambridge, MA); anti-Runx2 (catalog number 12556; Cell Signaling Technology, Beverly, MA); anti-E-cadherin (catalog number 610405; BD Biosciences, Franklin Lakes, NJ); anti- $\beta$-catenin (catalog number 8480 ; Cell Signaling Technology); and anti-glyceraldehyde-3phosphate dehydrogenase (Zhonshanjinqiao, Wuhan, China). Image acquisition of the blots was performed using a Gene5 image acquisition system (Syngene, Frederick, MD). 
Relative quantification of blots was determined by measuring the intensity of the protein bands with the use of Gel-Pro Analyzer (Media Cybernetics, Sarasota, FL).

\section{Quantitative Real-Time PCR}

RNA and protein lysate extraction, cDNA synthesis, and final real-time PCR were performed according to general protocols. $^{22}$ The mRNA levels of various genes were calculated with the $2^{-\Delta \Delta C T}$ method after normalizing with glyceraldehyde 3-phosphate dehydrogenase (Gapdh). The specific sequences of the primer pairs are given in Table 2.

\section{Immunofluorescence}

Both cells were fixed with $4 \%$ paraformaldehyde, permeabilized with $0.5 \%$ Triton X-100 in PBS, and blocked with 3\% bovine serum albumin in PBS. Cells were incubated with Runx2, E-cadherin, vimentin, FSP1, and collagen I primary antibodies overnight at $4^{\circ} \mathrm{C}$. After incubation with primary antibodies, the cell sections were stained with Alexa Fluor 488- or Alexa Fluor 594-conjugated secondary antibodies (Zhonshanjinqiao). Nuclei were counterstained with DAPI staining solution (Beyotime, Shanghai, China). All images were viewed using an Olympus FV3000 confocal scanning microscope.

\section{Immunohistochemistry}

Deparaffinized colon sections were immunoassayed for FSP1, PTH1R, Runx2, PTHLH, E-cadherin, vimentin, and $\beta$-catenin. The immunostaining was examined with an Olympus IX73 microscope (Olympus). The immunohistochemistry scoring analysis of tissue slices was evaluated by two pathologists in a blinded manner. The estimated percentage of staining was determined by calculating the average percentage of stained cells in three to four microscopic fields under 400-fold magnification. According to general evaluation standards, the proportion of positively staining cells was scored as 0 to 4 . Positive staining $<5 \%$ was defined as 0 , positive staining of $6 \%$ to $25 \%$ was defined as 1 , and positive staining of $26 \%$ to $50 \%$ was defined as 2 . Positive staining of $51 \%$ to $75 \%$ was defined as 3, and a staining ratio $>75 \%$ was defined as 4 . Meanwhile, staining intensity was graded as follows: 0, negative; 1 , weak; 2 , moderate; and 3, strong. Meanwhile, the immunoreactivity score for each slice, ranging from 0 to 12 , was determined as immunostaining intensity multiplied by the percentage of positive cells. $\beta$-Catenin-positive staining and $\beta$-catenin-positive nuclei staining were calculated and were used for analysis.

\section{Statistical Analysis}

All experiments were repeated at least three times. The results are presented as the means \pm SEM. SPSS 20.0 software (SPSS Inc., Chicago, IL) was used for analysis.
$U$-tests were used to assess the expression of PTHLH, PTH1R, FSP1, E-cadherin, vimentin, $\beta$-catenin, and Runx2 in CD and normal tissues. Pearson correlation and linear regression analysis were used to assess the correlations among PTHLH, PTH1R, fibrotic area, and Runx2. Multiple comparisons were performed with one-way analysis of variance. $P<0.05$ was considered statistically significant.

\section{Results}

PTHLH and PTH1R Expression Is Markedly Increased in Intestinal Epithelial Cells of CD Tissues

To investigate the potential role of PTHLH in CD, the levels of PTHLH and PTH1R were examined in CD tissues. A total of $31 \mathrm{CD}$ patients and 17 healthy volunteers were enrolled in this study. First, Masson's trichrome stain was used to visualize collagen fibers and identify fibrotic areas in $\mathrm{CD}$ tissues, whereas immunostaining was performed to confirm the expression of PTHLH and PTH1R. Collagen fiber deposition was detected in the mucosa of CD tissues (Figure 1A). In healthy tissues, PTHLH immunoreactivity was weak in intestinal epithelial cells but moderate in the inflammatory cells of the lamina propria layer, and PTH1R was scarce in both cell types (Figure 1A). However, most of the CD patients showed an increase in PTHLH and PTH1R staining in and around the fibrotic areas of the intestinal CD tissues. The immunoreactive scores revealed a nearly twofold and 100-fold intensity increase in PTHLH and PTH1R immunostaining, respectively, in CD tissues compared with those in normal intestinal tissues (Figure 1A). PTHLH and PTH1R were predominantly detected in the cytoplasm and nuclei of intestinal epithelial cells and the inflammatory cells in the lamina propria layer, with the highest expression in intestinal epithelial cells. Hence, it is likely that PTHLH-PTH1R axis expression in intestinal tissues might be involved in CD.

\section{The PTHLH/PTH1R System Correlates with Intestinal Fibrosis and EMT Marker Expression in CD}

Some studies have suggested that PTHLH contributes to renal fibrosis via EMT. ${ }^{35}$ Immunostaining analysis was used to confirm the presence of EMT-related markers. As in previous reports, the presence of EMT was confirmed in human CD tissues. ${ }^{21,22}$ Expression of the epithelial cell marker E-cadherin, the mesenchymal cell marker vimentin, the myofibroblast marker FPS1, and the onset of EMT marker nuclear localization of $\beta$-catenin was detected using immunohistochemistry. E-cadherin expression in normal intestinal epithelial cells displayed more intense staining than in CD tissues (Figure 1B). In contrast, positive immunostaining for vimentin and FPS1 showed increased intensities in the CD fibrotic area, and these proteins were quantified in the whole tissue, including the epithelial cells 
A
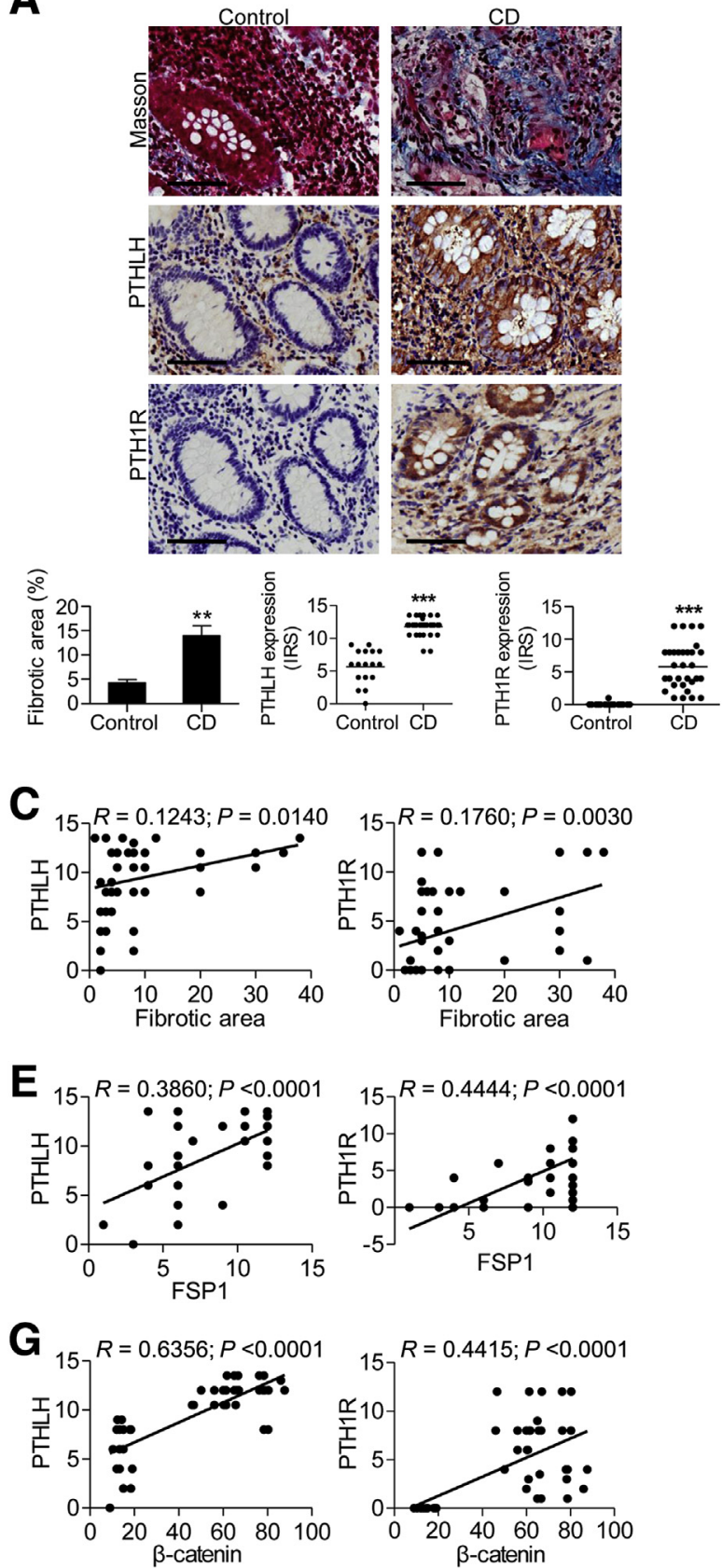

B
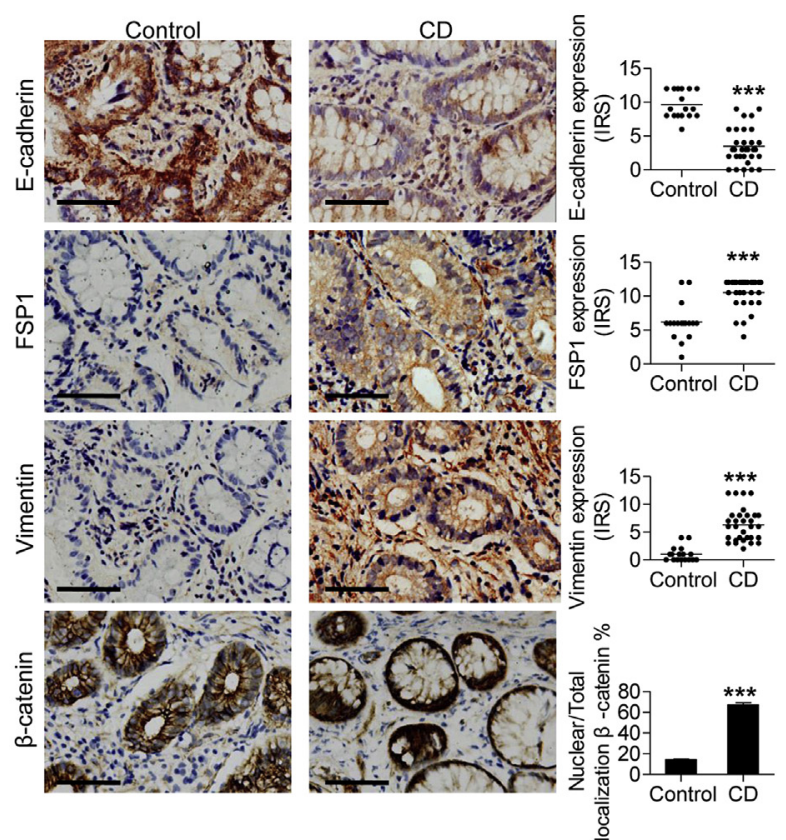

D
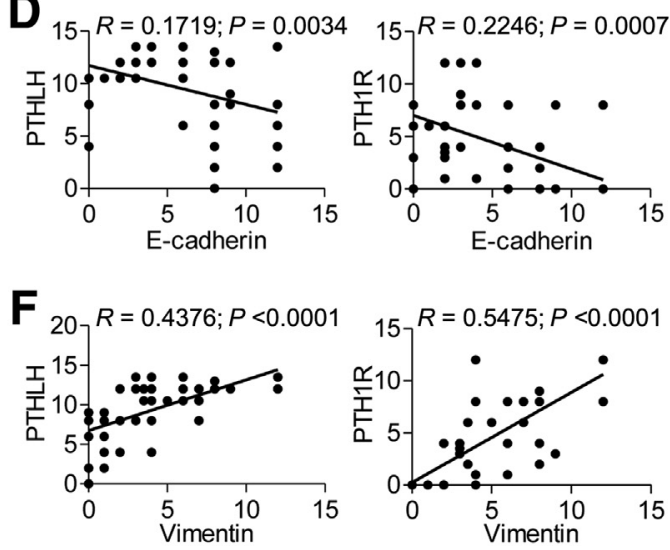

Figure 1 PTHLH/PTH1R increases in the intestine of Crohn disease (CD) patients and correlates with fibrotic area and epithelial-to-mesenchymal transition in CD tissues. A: Representative micrographs of Masson's trichrome staining and quantitative determination of the relative fibrotic area in healthy controls and CD patients are presented. Representative images of immunostaining showing the localization of PTHLH and PTH1R in intestinal sections from healthy volunteers and CD patients; immunostaining reveals an increased deposition of PTHLH and PTH1R in intestinal sections from 31 CD patients. Normal intestinal tissues were from 17 healthy individuals (controls). Data for the accompanying graphs were generated from immunoreactive scores (IRSs). B: Immunohistochemical staining showing the localization of E-cadherin, fibroblast-specific protein (FSP) 1 , vimentin, and $\beta$-catenin in intestinal tissues from controls and CD patients. Data for the accompanying graphs were generated from IRSs or quantitative determination. $\mathbf{C}$ and $\mathbf{E}-\mathbf{G}$ : Pearson correlation and linear analysis reveal that the fibrotic area and the increased levels of FSP1, vimentin, and nuclear localization of $\beta$-catenin expression are positively associated with PTHLH/ PTH1R accumulation in intestinal sections of CD patients. D: Pearson correlation and linear analysis showing that PTHLH and PTH1R expression is negatively associated with E-cadherin expression in lesion tissues from CD patients. ${ }^{* *} P<0.01,{ }^{* * *} P<0.001$ versus controls. Scale bars $=50 \mu \mathrm{m}(\mathbf{A}$ and $\mathbf{B})$.

and stroma; at the same time, in $\mathrm{CD}$ patients, membrane staining of $\beta$-catenin was generally weaker than that in control patients, and more cells featured nuclear staining, indicating transcriptionally active $\beta$-catenin. These results confirmed the occurrence of EMT in human CD tissues. Next, Pearson correlation and linear regression analyses revealed that PTHLH and PTH1R accumulation was positively correlated with the fibrotic area (Figure 1C). Pearson 

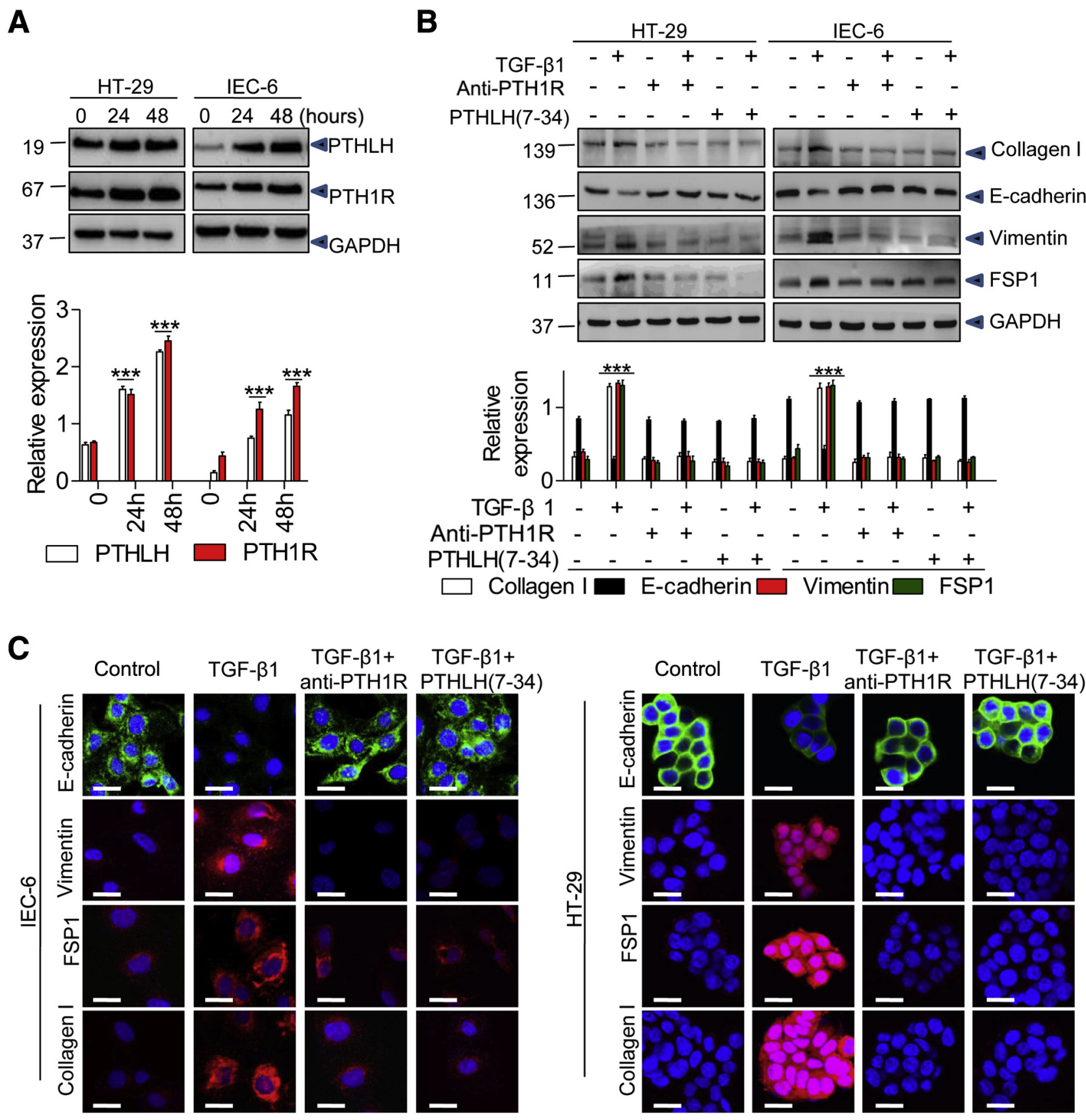

Figure 2 Transforming growth factor (TGF)- $\beta 1$ increases PTHLH/PTH1R protein expression, and inhibition of PTHLH/PTH1R can prevent the TGF- $\beta 1-$ induced epithelial-to-mesenchymal transition in intestinal epithelial cells. A: Confluent HT-29 and intestinal epithelial cell line (IEC)- 6 cells were incubated with $10 \mathrm{ng} / \mathrm{mL}$ TGF- $\beta 1$ for the indicated period. PTHLH and PTH1R protein expression was examined by Western blotting. B: HT- 29 and IEC- 6 cells were pretreated with $5 \mu \mathrm{g} / \mathrm{mL}$ neutralizing antibody targeting PTH1R or with $1 \mu \mathrm{mol} / \mathrm{L}$ PTHLH (1 to 40) antagonist PTHLH (7 to 34 ) for 2 hours and then incubated with $10 \mathrm{ng} / \mathrm{mL}$ TGF- $\beta 1$ for 48 hours, and then, the collagen I, E-cadherin, vimentin, and fibroblast-specific protein (FSP) 1 expression was examined by Western blotting. C: Immunofluorescence staining for E-cadherin (green), vimentin (red), FSP1 (red), and collagen I (red), and the nuclei were stained with DAPI. HT-29 and IEC- 6 cells were pretreated with 5 $\mu \mathrm{g} / \mathrm{mL}$ neutralizing antibody targeting PTH1R or with $1 \mu \mathrm{mol} / \mathrm{L}$ PTHLH (1 to 40) antagonist PTHLH (7 to 34 ) for 2 hours and then incubated with $10 \mathrm{ng} / \mathrm{mL}$ TGF- $\beta 1$ for 48 hours. Relative protein levels of PTHLH, PTH1R, collagen I, E-cadherin, vimentin, and FSP1 were normalized with glyceraldehyde-3-phosphate dehydrogenase (GAPDH). Data are expressed as means \pm SEM $(\mathbf{A}$ and $\mathbf{B}) . n=3$ independent experiments $(\mathbf{A}$ and $\mathbf{B}) .{ }^{* * *} P<0.001$ versus controls. Scale bars $=25 \mu \mathrm{m}(\mathbf{C})$.

correlation and linear regression analyses were performed to confirm the relationships among PTHLH, PTH1R, and EMT markers, and the results revealed that PTHLH and PTH1R accumulation had a close negative correlation with E-cadherin expression in CD tissues (Figure 1D), whereas increased nuclear localization of $\beta$-catenin and high vimentin and FSP1 levels positively associated with the PTHLH/PTH1R system (Figure 1, E-G). The PTHLH/ PTH1R system seems to be significant in the process of EMT during intestinal fibrosis. 
A

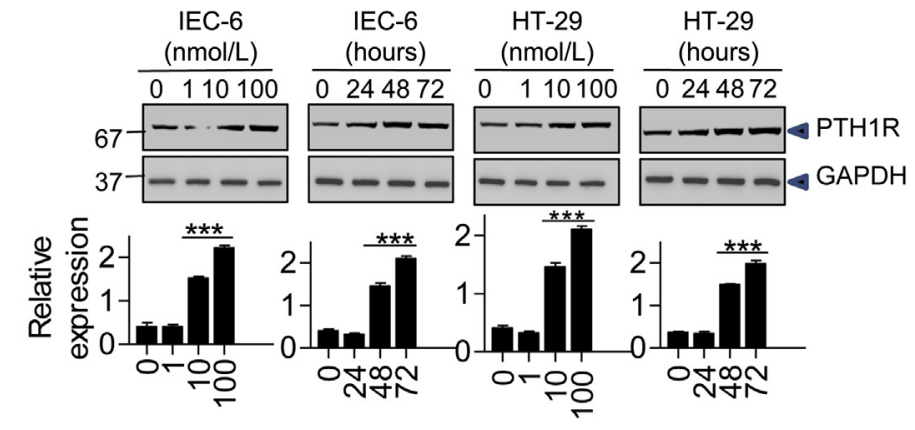

C

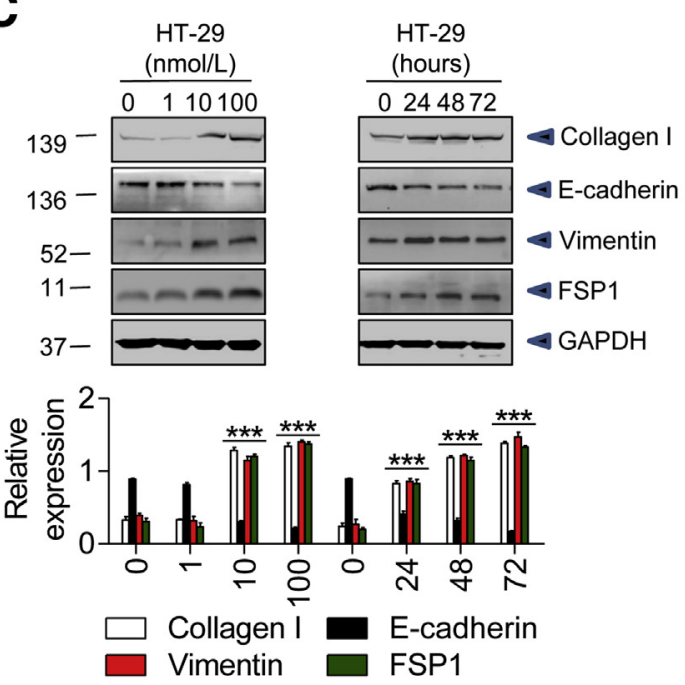

B

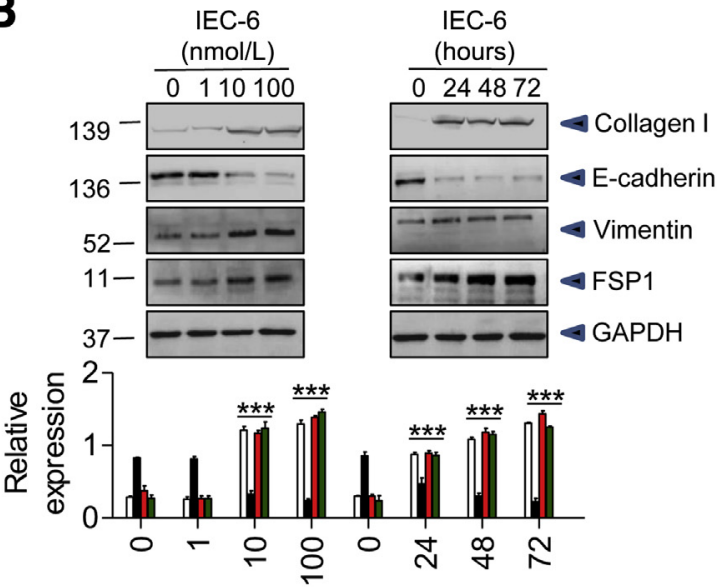

D

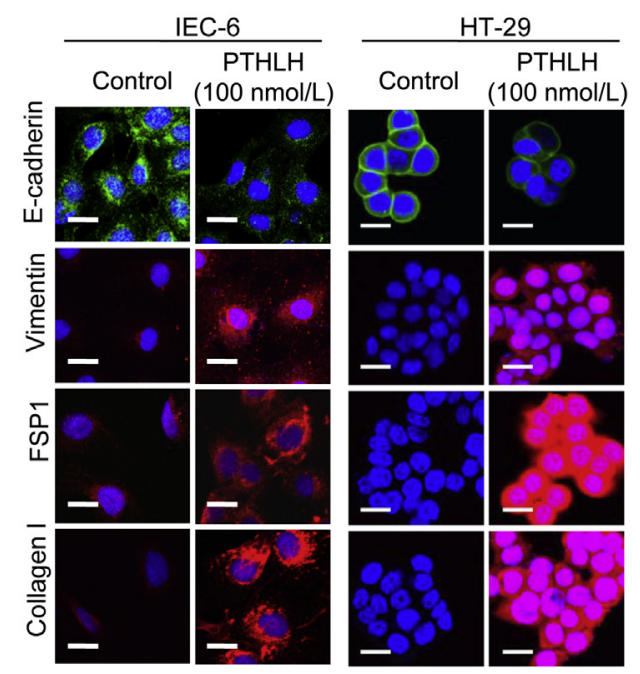

Figure 3 PTHLH (1 to 40) treatment regulates the expression of epithelial-to-mesenchymal transition markers in a concentration- and time-dependent manner in both HT-29 and intestinal epithelial cell line (IEC)- 6 cells. HT-29 and IEC- 6 cells were incubated with the indicated concentrations of PTHLH (1 to 40 ) for 48 hours or with $100 \mathrm{nmol} / \mathrm{L}$ PTHLH $(1$ to 40$)$ for the indicated time periods. A: The protein expression of PTH1R was determined by Western blotting. B and C: The protein expression of E-cadherin, vimentin, fibroblast-specific protein (FSP) 1, and collagen I was determined by Western blotting. D: Immunofluorescence staining for E-cadherin (green), vimentin (red), FSP1 (red), and collagen I (red); the nuclei were stained with DAPI. HT-29 and IEC-6 cells were treated with $100 \mathrm{nmol} / \mathrm{L}$ PTHLH (1 to 40) for 48 hours. Relative protein levels of PTH1R, collagen I, E-cadherin, vimentin, and FSP1 were normalized versus glyceraldehyde-3-phosphate dehydrogenase (GAPDH). Data are expressed as means \pm SEM (A-C). $n=3$ independent experiments $(\mathbf{A}-\mathbf{C})$. $* * * P<0.001$ versus controls. Scale bars $=25 \mu \mathrm{m}$ (D).

\section{PTHLH Is an Important Mediator of TGF- $\beta 1$}

Given the central role of TGF- $\beta 1$ in the pathogenesis of intestinal fibrosis and that PTHLH serves as a primary mediator of TGF- $\beta$ in tumor cells and keratinocytes, ${ }^{10,21,25-29,52}$ it was examined whether TGF- $\beta 1$ modulated the expression of the PTHLH/PTH1R system in intestinal epithelial cells. IEC-6 and HT-29 were chosen as in vitro models. Both cell lines were incubated with $10 \mathrm{ng} / \mathrm{mL}$ TGF- $\beta 1$ for various periods. The Western blotting results demonstrated a time-dependent increase in PTHLH and PTH1R protein levels (Figure 2A). To confirm whether PTHLH was required for TGF- $\beta 1$-induced EMT in intestinal epithelial cells, IEC-6 and HT-29 cells were pretreated with neutralizing antibody targeting PTH1R and with the PTHLH (1 to 40) antagonist PTHLH (7 to 34$).{ }^{53}$ Neutralization of
PTH1R and inhibition of PTHLH (1 to 40) bioactivity significantly increased E-cadherin expression and suppressed vimentin, FSP1, and collagen I at the protein level in TGF- $\beta 1$-treated cells (Figure 2B). Immunofluorescence confirmed that TGF- $\beta 1$-induced EMT was prevented by the neutralizing PTH1R antibody and PTHLH (7 to 34) (Figure 2C). These results further indicated that PTHLH was a major mediator of TGF- $\beta 1-$ induced EMT.

\section{PTHLH Induces EMT in Vitro}

On the basis of the above findings described above, we hypothesized that the PTHLH/PTH1R system may play an important role in the occurrence of EMT in intestinal epithelial cells. First, it was confirmed that PTHLH increased PTH1R expression in a dose- and time-dependent 

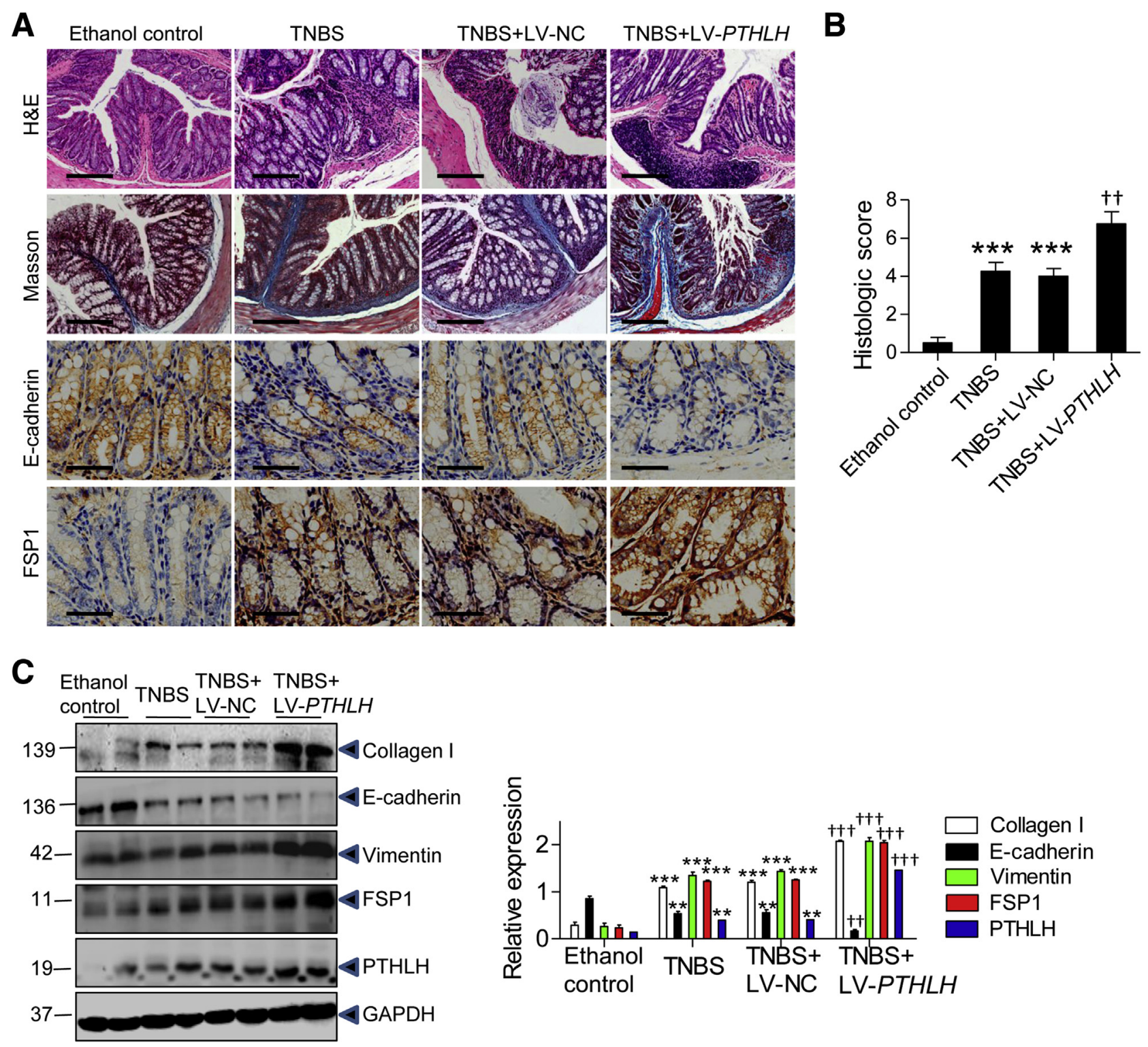

Figure 4 PTHLH promotes inflammation and fibrosis in the 2,4,6-trinitrobenzene sulfonic acid (TNBS)-induced intestinal fibrosis model. Chronic inflammation and fibrosis were induced by weekly rectal administration of TNBS for 7 weeks. Control mice received a weekly enema of $45 \%$ ethanol alone (vehicle). Treatment with LV-NC or LV-PTHLH was initiated in a subset of mice 48 hours before the first TNBS enema and continued weekly for the duration of the study. A: Paraffin-embedded colonic tissue sections were labeled with hematoxylin and eosin (H\&E) or Masson's trichrome stain (MTS). Immunohistochemical staining with E-cadherin and fibroblast-specific protein (FSP) 1 antibodies was performed on paraffin-embedded colonic tissue sections. B: Histologic scores in colonic tissue from the same groups described above. C: Representative Western blots showing the protein levels of E-cadherin, vimentin, FSP1, collagen I, and PTHLH in colonic tissues (whole intestinal tissue) in the indicated group. Relative protein levels of PTHLH, collagen I, E-cadherin, vimentin, and FSP1 were normalized with glyceraldehyde-3-phosphate dehydrogenase (GAPDH). Data are expressed as means \pm SEM (B and C). $n=5$ for all groups. ${ }^{* *} P<0.01,{ }^{* *} P<0.001$ versus vehicles; ${ }^{\dagger \dagger} P<0.01,{ }^{\dagger \dagger} P<0.001$ versus the TNBS-treated group. Scale bars: $100 \mu \mathrm{m}$ (A, sections labeled with H\&E and MTS); $50 \mu \mathrm{m}$ (A, sections stained with E-cadherin and FSP1).

manner (Figure 3A). To investigate whether the PTHLH/ PTH1R system directly induced EMT in intestinal epithelial cells, PTHLH (1 to 40) was administered to IEC6 and HT-29 cells. Immunoblot analysis showed that PTHLH (1 to 40) significantly increased vimentin and FSP1 expression and reduced E-cadherin expression in a concentration- and time-dependent manner (Figure 3, B and C). In addition, exposure to PTHLH (1 to 40) resulted in an increase in the expression of collagen I, an ECM component (Figure 3, B and C). Furthermore, immunofluorescence analysis confirmed that PTHLH (1 to 40) induced acquisition of an intestinal epithelial cell fibroblast-like phenotype and collagen production (Figure 3D). Hence, PTHLH (1 to 40) stimulation promoted the onset of EMT and matrix production in intestinal epithelial cells. 


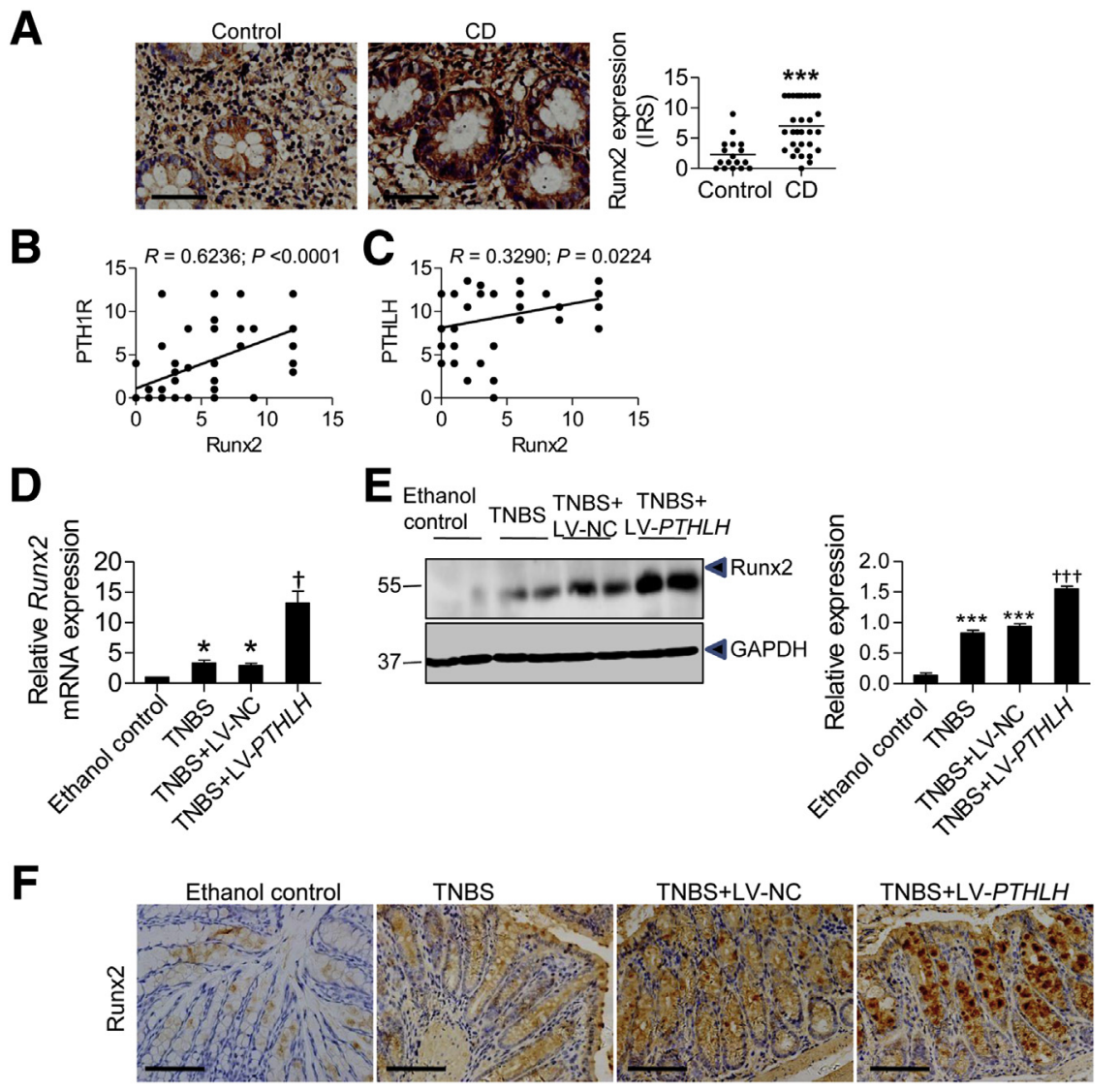

Figure 5 PTHLH increases Runx2 expression in vitro. A: Immunohistochemical staining for Runx2 expression in intestinal sections from 31 Crohn disease (CD) patients or 17 control subjects. B and C: Pearson correlation and linear analysis shows that Runx2 expression was positively associated with PTHLH/PTH1R expression in intestinal tissues. D: Bar graphs representing real-time quantitative PCR analysis show the Runx2 mRNA levels in mice treated as described above. E: Representative Western blots showing the protein levels of Runx2 in colonic tissues. F: Immunohistochemical staining for Runx2 expression in intestinal sections from mice treated as described above. The relative mRNA and protein levels are expressed as a fold induction over the levels in the vehicle-treated group after normalization to glyceraldehyde-3-phosphate dehydrogenase (GAPDH). Data are expressed as means \pm SEM (A, D, and E). $n=5$ in all groups. ${ }^{*} P<0.05,{ }^{* *} P<0.001$ versus ethanol; ${ }^{\dagger} P<0.05,{ }^{\dagger \dagger} P<0.001$ versus the $2,4,6$ trinitrobenzene sulfonic acid (TNBS)-treated group. Scale bars $=50 \mu \mathrm{m}(\mathbf{A}$ and $\mathbf{F})$. IRS, immunoreactive score.

\section{PTHLH Gene Delivery Aggravates TNBS-Induced EMT and Intestinal Fibrosis}

To investigate whether PTHLH overexpression augmented the severity of intestinal fibrosis, LV-NC or LV-PTHLH was intraperitoneally injected into mice, and intestinal tissues were harvested after 7 weeks; $50 \%$ survival was observed in the three TNBS-treated groups. After TNBS enemas for 7 weeks, histologic examination using hematoxylin and eosin staining revealed that mice inoculated with $45 \%$ ethanol did not show histologic evidence of tissue injury (Figure 4A). In contrast, TNBS administration resulted in mucosal ulcerations, with granulation tissue at the base and a transmural inflammatory response, and TNBS-treated LV-PTHLH mice exhibited more severe intestinal injury and fibrosis than mice treated with TNBS alone and TNBS-treated LV-NC mice, as assessed with hematoxylin and eosin staining and Masson's trichrome stain (Figure 4A). The histologic score also demonstrated that LV-PTHLH administration was effective in promoting inflammation and fibrosis (Figure 4B). In 45\% ethanol-treated mice, E-cadherin was regularly and strongly expressed at cell-cell contacts in the colonic epithelium. In mice treated with TNBS alone and TNBS-treated LV-NC mice, E-cadherin staining was decreased in the intestinal epithelium, but LVPTHLH mice showed dramatically decreased staining at the cell-cell walls after TNBS treatment for 7 weeks (Figure 4A).
The staining intensity of FSP1, a fibroblast marker in mouse colonic tissue, was next examined. Compared with the weak expression in intestinal epithelial cells from $45 \%$ ethanoltreated mice, moderately increased FSP1 expression was observed in mice treated with TNBS alone and TNBS-treated LV-NC mice, and LV-PTHLH mice exhibited a dramatic increase in FSP1 expression (Figure 4A). The occurrence of EMT was also confirmed by Western blot analysis, illustrating reduced E-cadherin expression and up-regulated vimentin, FSP1, and collagen I levels (Figure 4C). These results suggested that PTHLH can promote EMT in vivo, leading to an increase in fibroblasts number and matrix deposition in the development of intestinal fibrosis.

\section{PTHLH (1 to 40) Triggers EMT in Intestinal Epithelial Cells through Activation of the PKA-Dependent Transcription Factor Runx2}

A previous study demonstrated that activation of the transcription factor Runx2 is responsible for the PTHLHinduced antiapoptotic effects in renal fibrosis, ${ }^{38}$ and Runx 2 is a well-known promoter of collagen type I. ${ }^{54,55}$ To confirm whether Runx 2 was also required for the PTHLH-induced EMT program in intestinal cells, the presence of Runx2 in intestinal fibrosis was first examined. CD tissues had significantly increased Runx2 immunostaining in the intestinal 
A

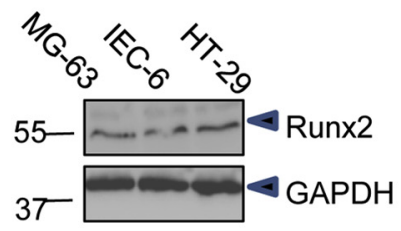

B

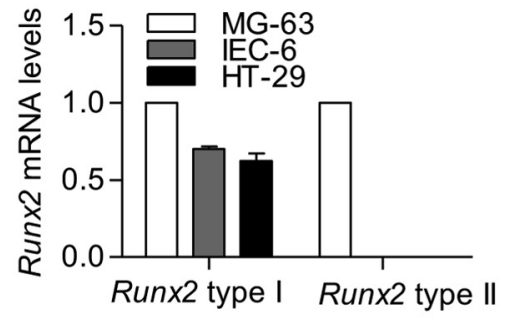

C

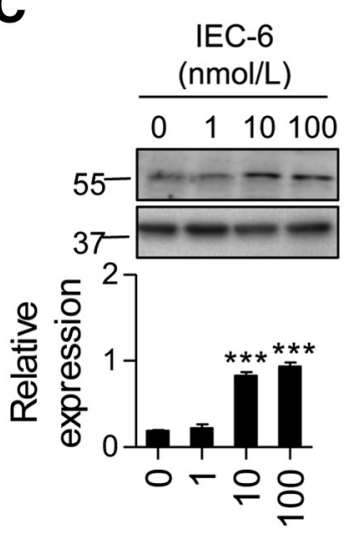

D

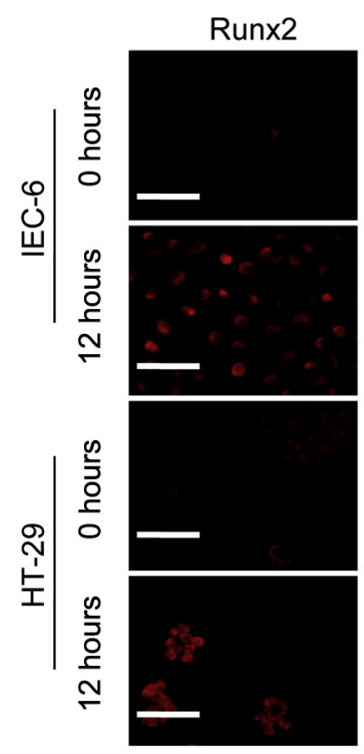

IEC-6 (hours)
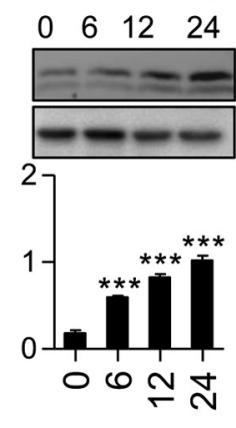
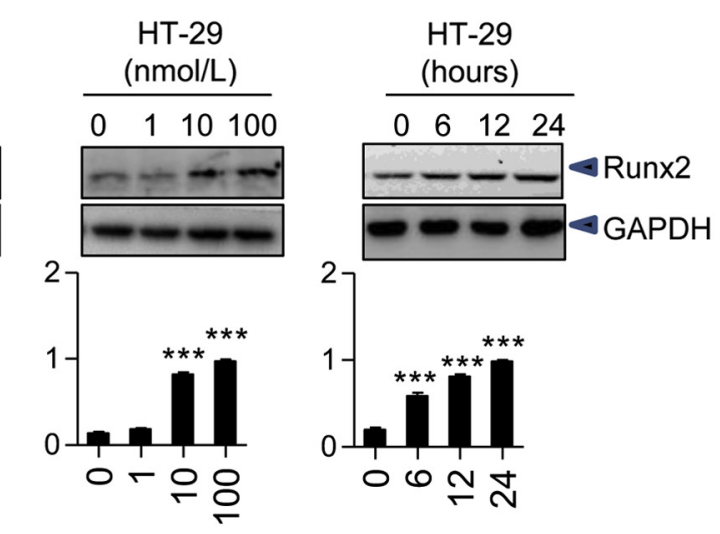

E

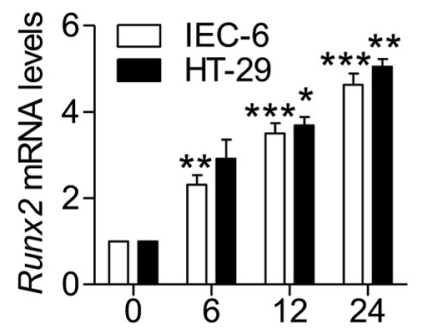

$\mathbf{F}$
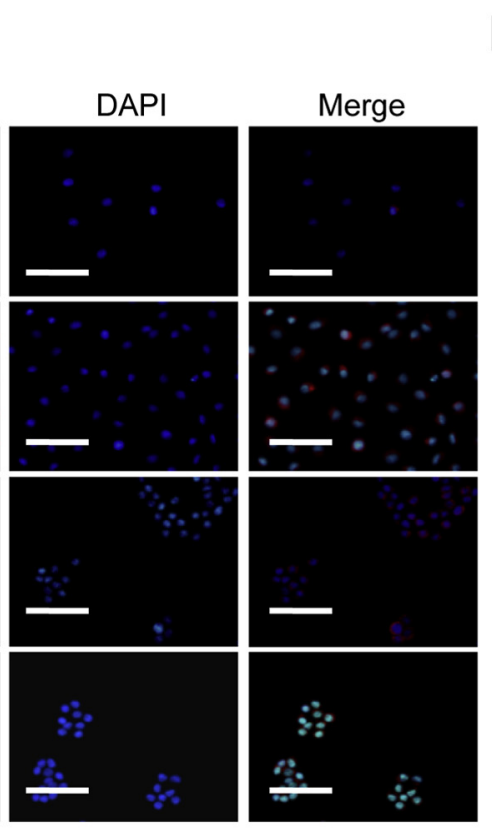

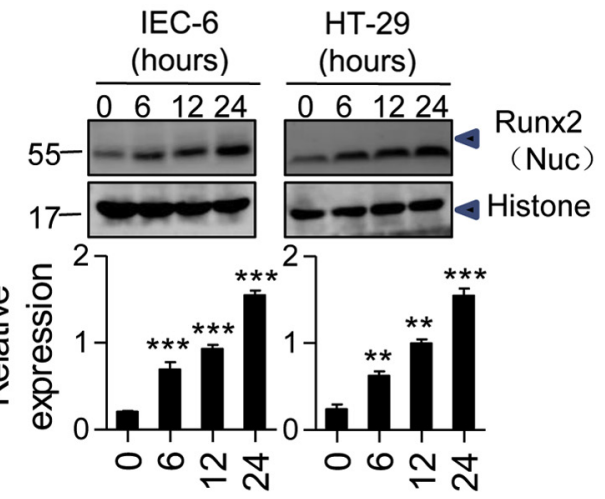

Figure 6 PTHLH (1 to 40) increases Runx2 expression and promotes nuclear localization in vitro. A: Western blotting analysis was used to determine Runx2 expression in osteoblast-like MG-63 cells (used as a Runx2-positive control) and intestinal epithelial cell line (IEC)-6 and HT-29 intestinal epithelial cells. Bands of $55 \mathrm{kDa}$ that correspond to the predicted size of Runx2 are shown. B: Real-time quantitative (qPCR) analysis shows the expression levels of Runx2 in MG-63 cells (used as a Runx2 type I and type II positive control) and IEC- 6 and HT-29 intestinal epithelial cells. Only Runx2 type I was detected in IEC-6 and HT-29 cells. C: HT-29 and IEC-6 cells were incubated with the indicated concentrations of PTHLH (1 to 40 ) for 48 hours or $100 \mu \mathrm{mol} / \mathrm{L}$ PTHLH (1 to 40 ) for the time periods indicated. The protein expression of Runx2 was determined by Western blotting. D: Immunofluorescence staining for Runx2. HT-29 and IEC- 6 cells were treated with $100 \mathrm{nmol} / \mathrm{L}$ PTHLH ( 1 to 40 ) for 12 hours. E: Bar graphs representing the qPCR analysis show the levels of Runx2 mRNA in both cell lines. F: Western blot analysis of nuclear extracts from HT-29 and IEC- 6 cells stimulated with $100 \mathrm{nmol} / \mathrm{L}$ PTHLH (1 to 46) for different lengths of time. Relative protein levels were normalized to histone expression. The relative mRNA and protein levels are expressed as a fold induction over the level in the vehicle-treated group after normalization to glyceraldehyde-3-phosphate dehydrogenase (GAPDH). Data are expressed as means \pm SEM $(\mathbf{C}, \mathbf{E}$, and $\mathbf{F}) . n=3$ independent experiments (C, E, and F). ${ }^{*} P<0.05,{ }^{* * P}<0.01$, and ${ }^{* * * P}<0.001$ versus controls. Scale bars $=100 \mu \mathrm{m}$ (D). 
A

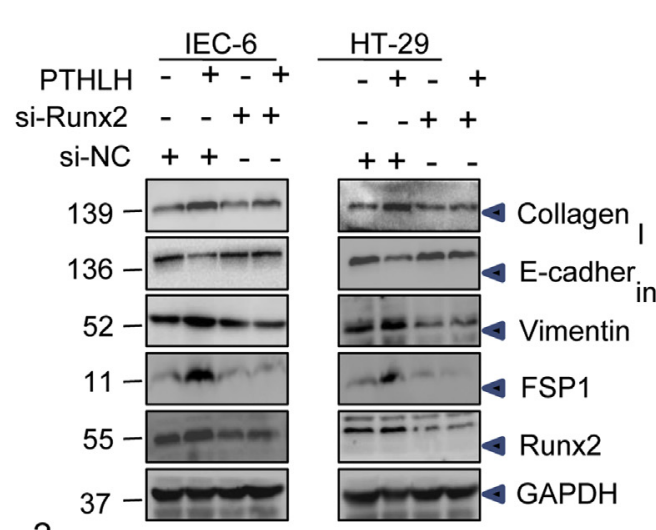

B

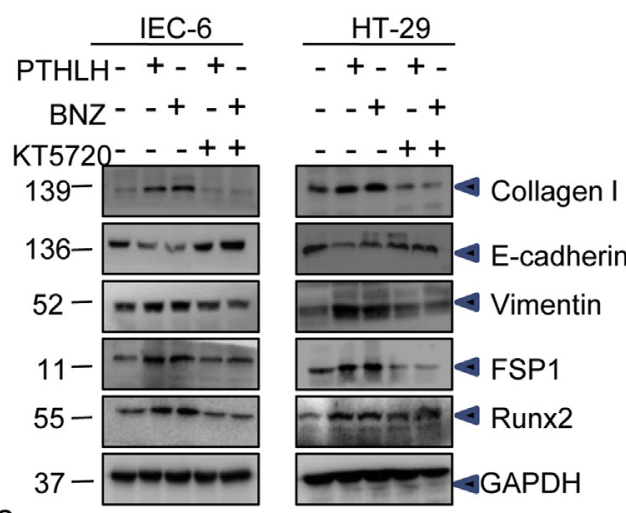

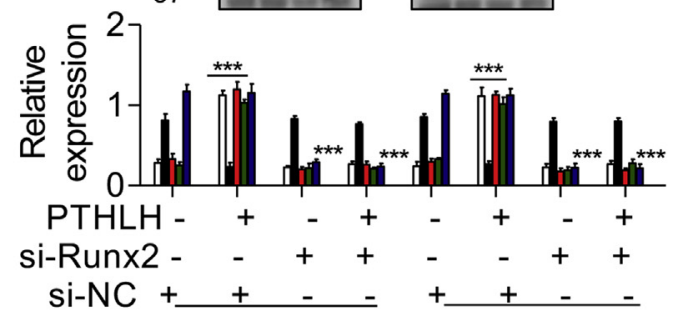

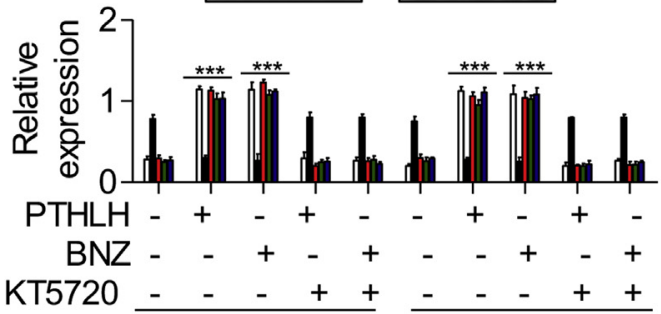

Collagen I E-cadherin $\square$ Vimentin FSP1 Runx2

C

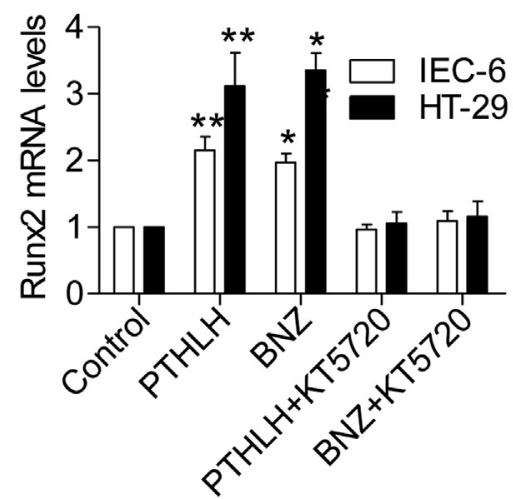

D

Collagen I E-cadherin $\square$ Vimentin

$\square$ FSP1 $\square$ Runx2

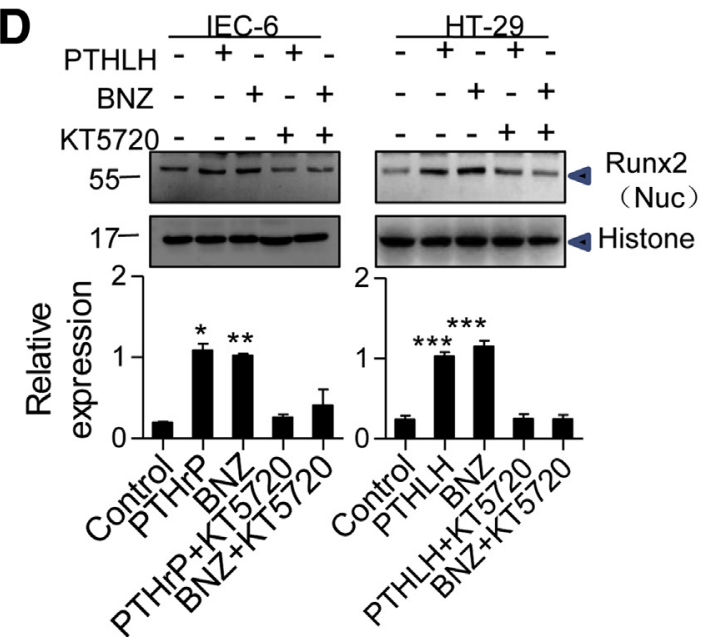

Figure 7 PTHLH (1 to 40)-induced epithelial-to-mesenchymal transition is mediated by Runx2 and mediates Runx2 expression via activation of protein kinase A in vitro. A: HT-29 and intestinal epithelial cell line (IEC)- 6 cells were transfected with small interfering (si)-NC or si-Runx2 for 24 hours and then treated with PTHLH (1 to 40) for another 48 hours. Representative Western blots show the protein levels of E-cadherin, vimentin, fibroblast-specific protein (FSP) 1, collagen I, and Runx2. B and C: HT-29 and IEC-6 cells were pretreated with $200 \mu \mathrm{mol} / \mathrm{L} \mathrm{KT5720}$ for 2 hours and subsequently exposed to $100 \mathrm{nmol} / \mathrm{L}$ PTHLH (1 to 40) or $100 \mu \mathrm{mol} / \mathrm{L}$ N6-benzoyladenosine--3', $5^{\prime}$-cyclic monophosphate (BNZ) for 48 hours. B: Representative Western blots show the protein levels of E-cadherin, vimentin, FSP1, collagen I, and Runx2 in both cell lines. C: Bar graphs representing the real-time quantitative PCR analysis show the levels of Runx2 mRNA in both cell lines. D: Western blot analysis of nuclear extracts from HT-29 and IEC- 6 cells. The relative mRNA and protein levels are expressed as a fold induction over those in control cells after normalization to glyceraldehyde-3-phosphate dehydrogenase (GAPDH). Data are expressed as means \pm SEM (A-D). $n=3$ (A-D). ${ }^{*} P<0.05,{ }^{* *} P<0.01$, and ${ }^{* * *} P<0.001$ versus controls.

epithelial cells (Figure 5A). Pearson correlation and linear regression analyses were next performed to confirm the relationships among PTHLH, PTH1R, and Runx2, and the results revealed that PTHLH and PTH1R accumulation was closely correlated with Runx2 expression in $\mathrm{CD}$ tissues (Figure 5, B and C). To further confirm the effect of PTHLH on Runx2 promotion in vivo, the presence of Runx 2 was examined in the intestinal fibrosis model. Compared with the weak expression in intestinal epithelial cells from $45 \%$ ethanol-treated mice, moderately increased Runx 2 expression was observed in mice treated with TNBS alone and in TNBS-treated LV-NC mice, and LV-PTHLH mice showed dramatically increased Runx 2 expression at both the mRNA and protein levels (Figure 5, D-F). Collectively, these results indicated that Runx2 was regulated by PTHLH in intestinal fibrosis. 
Next, the mechanism by which Runx 2 is involved in PTHLH-induced EMT in intestinal epithelial cells was explored. Both HT-29 and IEC-6 cells express Runx 2 in basal conditions (Figure 6A). As previously reported, of the two major isoforms of Runx2 observed in osteoblasts (eg, the MG-63 cell line, which is an osteoblast-like cell line used as a positive control for Runx 2 expression), type I and type II, ${ }^{38}$ only Runx 2 type I was detected in HT-29 and IEC- 6 cells (Figure 6B). Next, we hypothesized that PTHLH (1 to 40) can similarly regulate the expression of Runx 2 type I in intestinal epithelial cells. PTHLH (1 to 40) treatment significantly increased Runx 2 expression in a dose- and time-dependent manner (Figure 6C).

Runx 2 transcriptional activity requires its translocation from the cytoplasm to the nucleus. ${ }^{38,56}$ Herein, it was found that PTHLH (1 to 40) promotes Runx2 nuclear localization in both cell lines. Nuclear distribution of Runx 2 showing colocalization with the fluorescent nuclear stain DAPI was observed by immunofluorescence after PTHLH ( 1 to 40) stimulation for 12 hours (Figure 6D). Furthermore, Runx2 mRNA levels were increased after 6 hours of stimulation with PTHLH (1 to 40) and remained elevated (Figure $6 \mathrm{E}$ ). Runx 2 protein levels from cell nuclear extracts were increased after 6 hours of stimulation with PTHLH (1 to 40) and remained elevated throughout the study (24 hours) (Figure 6F). To assess whether Runx2 is a mediator of PTHLH (1 to 40)-induced EMT in cultured intestinal epithelial cells, both cell lines were preincubated with small interfering Runx2 and then incubated with PTHLH (1 to 40 ) for 48 hours. Small interfering Runx 2 significantly restored the protein level of E-cadherin and attenuated PTHLH (1 to 40)-induced vimentin, FSP1, and collagen I protein expression (Figure 7A).

A previous study demonstrated that PTH1R signals primarily by coupling with PKA, and PTH (1 to 34) modulates Runx2 in osteoblasts through activation of the PKA pathway. ${ }^{57,58}$ To determine whether PTHLH (1 to 40) triggered Runx2 activation through the PKA pathway, both cell lines were pretreated with a PKA inhibitor (KT5720) and then treated with PTHLH (1 to 40) or a PKA activator (N6-benzoyladenosine- $3^{\prime}, 5^{\prime}$-cyclic monophosphate). PTHLH (1 to 40) - and N6-benzoyladenosine- $3^{\prime}, 5^{\prime}$ cyclic monophosphate-induced EMT was suppressed by KT5720 (Figure 7B). Meanwhile, pretreatment of HT-29 and IEC-6 cells with KT5720 suppressed the PTHLH (1 to 40)- and N6-benzoyladenosine- $3^{\prime}, 5^{\prime}$-cyclic monophosphate-induced Runx2 increase at both the mRNA and protein levels (Figure 7, B and C). Runx2 protein levels from cell nuclear extracts were also suppressed by KT5720 (Figure 7D). These data demonstrated that PKA activation serves as an upstream event in PTHLH-induced Runx2 activation.

\section{Discussion}

Intestinal fibrosis is a well-described complication of long-standing $\mathrm{CD}$ and is thought to occur because of chronic inflammation and dysregulated wound healing. ${ }^{21}$
Myofibroblasts contribute to ECM deposition. ${ }^{20}$ Recently, epithelial cells exposed to profibrotic stimuli have been shown to lose polarity and acquire a mesenchymal phenotype via EMT in $\mathrm{CD}$ and in $\mathrm{CD}$ complications, including fistulas and fibrosis. ${ }^{12,18,20,21}$ However, the molecular mechanisms underlying this process are unclear. This study showed that the PTHLH/PTH1R/PKA/Runx2 axis contributes to intestinal fibrosis in vitro and in vivo. The PTHLH/ PTH1R system was aberrantly expressed in intestinal fibrotic tissues from CD patients, and PTHLH/PTH1R accumulation was associated with fibrotic area and EMT marker expression. TGF- $\beta 1$ induced PTHLH/PTH1R expression. More important, PTHLH treatment promoted the EMT program in intestinal epithelial cells. Activation of the PKA-dependent transcription factor Runx2 was required for PTHLH-induced EMT in intestinal epithelial cells. These results emphasize the importance of PTHLH at the onset of EMT and establish a role for the PTHLH/PTH1R system in intestinal fibrosis.

PTHLH is a multifunctional factor expressed in almost all normal tissues. The structure of PTHLH is similar to that of PTH, particularly the N-terminal amino acid sequence, and its full biological activity is contained within the first 34 amino acids. ${ }^{29}$ Generally, PTHLH exerts its pathologic effects through PTH1R, and PTHLH is known to be involved in the process of collagen I deposition during osteoblast activity. ${ }^{59}$ Recently, studies have shown that PTHLH interacts with TGF- $\beta 1$ and can promote fibrogenesis in obstructed mouse kidney and chronic pancreatitis. ${ }^{37,40}$ PTHLH (1 to 36) can activate hepatic stellate cells. ${ }^{36}$ PTHLH also mediates the death of intestinal epithelial cells. $^{42,43}$ More extensive knowledge of PTHLH has revealed that excessive PTHLH expression under pathologic conditions also participates in EMT in renal fibrosis. ${ }^{35}$ Thus, the present finding that PTHLH induced not only EMT but also apoptosis in intestinal epithelial cells may support the idea that increased PTHLH levels play an important role in intestinal fibrosis in $\mathrm{CD}$, similarly to other fibrotic diseases. Herein, excessive PTHLH/PTH1R system accumulation in intestinal sections from patients with $\mathrm{CD}$ was found for the first time. Moreover, accumulation of the PTHLH/PTH1R system correlated with the fibrotic area and EMT in CD tissues, suggesting that the PTHLH/PTH1R system mediates EMT in intestinal epithelial cells to promote intestinal fibrosis.

Previous studies support a molecular mechanism in which PTHLH is the major mediator of TGF- $\beta$-induced osteolysis in tumors and keratinocytes. ${ }^{25-29}$ Herein, profibrosis cytokines in the intestinal mucosa of CD patients were studied. TGF- $\beta 1$ is considered to be the most potent fibrogenic cytokine in most types of fibrosis, including CD-associated fibrosis. ${ }^{20,21,50}$ Indeed, in this study, it was confirmed that TGF- $\beta 1$ stimulation increased PTHLH and PTH1R expression in HT-29 and IEC-6 cells. Moreover, the data demonstrated that blocking the PTHLH/PTH1R system effectively attenuated TGF- $\beta 1$-induced EMT and collagen 
fiber synthesis. These results suggested that TGF- $\beta 1$ acts upstream of PTHLH, and thus, further research examining the role of PTHLH in TGF- $\beta 1$-induced fibrosis, which may provide new therapeutic targets for $\mathrm{CD}$ and its associated complications, should be conducted.

Next, for the major focus of the present study, the effect of PTHLH was investigated on both cell lines. First, PTHLH treatment reduced E-cadherin membrane expression and enhanced vimentin, FSP1, and collagen I expression in intestinal epithelial cells. In addition, the effects of PTHLH were assessed on TNBS-induced chronic colitis and fibrosis in mice. The microscopic inflammatory lesions associated with chronic TNBS administration and the collagen deposition in the mucosal, submucosal, and serosal layers were aggravated by weekly i.p. injection of LVPTHLH compared with those of mice treated with TNBS alone or TNBS-treated LV-NC mice. Thus, the present and previous studies have shown that PTHLH/PTH1R challenge increases the severity of intestinal fibrosis through EMT in inflamed intestinal tissues.

PTH (1 to 34) stimulated Runx2 transcription through activation of the PKA pathway in osteoblasts. ${ }^{57,58}$ To further clarify how the PTHLH/PTH1R system stimulates EMT occurrence and collagen production in intestinal epithelial cells, it was examined whether Runx2 was increased in CD tissues. In this study, Runx2 positively correlated with PTHLH and PTH1R in CD tissues and PTHLH increased Runx2 expression in the TNBS model. In vitro, PTHLH (1 to 40) treatment increased Runx2 expression and promoted rapid and persistent Runx2 translocation from the cytoplasm to the nucleus in intestinal epithelial cells. In addition, the stimulatory effects of PTHLH on EMT-related markers and collagen I expression were blocked by small interfering Runx2. Moreover, PTHLH stimulation increased Runx 2 expression via PKA in HT-29 and IEC-6 cells, which is consistent with previous reports. ${ }^{38}$ Runx2 is known to have an important role in mediating processes that contribute to the pathogenesis of fibrosis. ${ }^{60}$ However, it is unclear how Runx2, a downstream molecule of the PTHLH/PTH1R system, is involved in EMT and collagen synthesis in intestinal epithelial cells. The present data are the first to demonstrate that PKARunx2 is a major signaling pathway in PTHLH-induced EMT and collagen production.

Severe mucosal tissue damage requiring efficient wound healing is the main feature of inflammatory bowel disease and its two entities, CD and ulcerative colitis. Increased PTHLH and PTH1R in intestinal specimens from patients with active CD suggests that the PTHLH/PTH1R system likely participates in human intestinal fibrosis. Therefore, we provide evidence that PTHLH is a promising target for antifibrotic therapy. However, what triggers increased fibrosis in some patients and not in others is still unclear, and the pooling of samples from patients with CD clearly limits the scope of our interpretation of these human data. Nevertheless, these data support a role for the PTHLH/
PTH1R system in active human CD. Whether the findings are unique to $\mathrm{CD}$ or merely a result of active inflammation remains to be established.

In conclusion, we demonstrated that accumulation of PTHLH/PTH1R induced EMT in intestinal epithelial cells and collagen fiber production, and this effect was primarily dependent on the PKA/Runx2 signaling pathway.

\section{Supplemental Data}

Supplemental material for this article can be found at https://doi.org/10.1016/j.ajpath.2018.03.003.

\section{References}

1. McCormick BA: Using Salmonella enterica serotype typhimurium to model intestinal fibrosis. Gastroenterology 2008, 134:872-875

2. Rieder F, Brenmoehl J, Leeb S, Scholmerich J, Rogler G: Wound healing and fibrosis in intestinal disease. Gut 2007, 56:130-139

3. Holvoet T, Devriese S, Castermans K, Boland S, Leysen D, Vandewynckel YP, Devisscher L, Van den Bossche L, Van Welden S, Dullaers M, Vandenbroucke RE, De Rycke R, Geboes K, Bourin A, Defert O, Hindryckx P, De Vos M, Laukens D: Treatment of intestinal fibrosis in experimental inflammatory bowel disease by the pleiotropic actions of a local Rho kinase inhibitor. Gastroenterology 2017, 153:1054-1067

4. Rieder F, Zimmermann EM, Remzi FH, Sandborn WJ: Crohn's disease complicated by strictures: a systematic review. Gut 2013, 62: 1072-1084

5. Cunningham MF, Docherty NG, Burke JP, O'Connell PR: S100A4 expression is increased in stricture fibroblasts from patients with fibrostenosing Crohn's disease and promotes intestinal fibroblast migration. Am J Physiol Gastrointest Liver Physiol 2010, 299: G457-G466

6. Chang CW, Wong JM, Tung CC, Shih IL, Wang HY, Wei SC: In testinal stricture in Crohn's disease. Intest Res 2015, 13:19-26

7. Baumgart DC, Sandborn WJ: Crohn's disease. Lancet 2012, 380: $1590-1605$

8. Bernstein CN, Loftus EV Jr, Ng SC, Lakatos PL, Moum B; Epidemiology and Natural History Task Force of the International Organization for the Study of Inflammatory Bowel Disease (IOIBD): Hospitalisations and surgery in Crohn's disease. Gut 2012, 61: 622-629

9. Li C, Kuemmerle JF: Mechanisms that mediate the development of fibrosis in patients with Crohn's disease. Inflamm Bowel Dis 2014, 20:1250-1258

10. Kalluri R, Weinberg RA: The basics of epithelial-mesenchymal transition. J Clin Invest 2009, 119:1420-1428

11. Zeisberg M, Kalluri R: The role of epithelial-to-mesenchymal transition in renal fibrosis. J Mol Med 2004, 82:175-181

12. Kalluri R, Neilson EG: Epithelial-mesenchymal transition and its implications for fibrosis. J Clin Invest 2003, 112:1776-1784

13. Iwano M, Plieth D, Danoff TM, Xue C, Okada H, Neilson EG: Evidence that fibroblasts derive from epithelium during tissue fibrosis. J Clin Invest 2002, 110:341-350

14. Zeisberg M, Yang C, Martino M, Duncan MB, Rieder F, Tanjore H, Kalluri R: Fibroblasts derive from hepatocytes in liver fibrosis via epithelial to mesenchymal transition. J Biol Chem 2007, 282: 23337-23347

15. Kim KK, Kugler MC, Wolters PJ, Robillard L, Galvez MG Brumwell AN, Sheppard D, Chapman HA: Alveolar epithelial cell mesenchymal transition develops in vivo during pulmonary fibrosis 
and is regulated by the extracellular matrix. Proc Natl Acad Sci U S A 2006, 103:13180-13185

16. Zeisberg EM, Tarnavski O, Zeisberg M, Dorfman AL, McMullen JR, Gustafsson E, Chandraker A, Yuan X, Pu WT, Roberts AB, Neilson EG, Sayegh MH, Izumo S, Kalluri R: Endothelial-to-mesenchymal transition contributes to cardiac fibrosis. Nat Med 2007, 13:952-961

17. Scharl M, Frei S, Pesch T, Kellermeier S, Arikkat J, Frei P, Fried M, Weber A, Jehle E, Ruhl A, Rogler G: Interleukin-13 and transforming growth factor beta synergise in the pathogenesis of human intestinal fistulae. Gut 2013, 62:63-72

18. Bataille F, Rohrmeier C, Bates R, Weber A, Rieder F, Brenmoehl J, Strauch U, Farkas S, Furst A, Hofstadter F, Scholmerich J, Herfarth H, Rogler G: Evidence for a role of epithelial mesenchymal transition during pathogenesis of fistulae in Crohn's disease. Inflamm Bowel Dis 2008, 14:1514-1527

19. Scharl M, Huber N, Lang S, Furst A, Jehle E, Rogler G: Hallmarks of epithelial to mesenchymal transition are detectable in Crohn's disease associated intestinal fibrosis. Clin Transl Med 2015, 4:1

20. Rieder F, Kessler SP, West GA, Bhilocha S, de la Motte C, Sadler TM, Gopalan B, Stylianou E, Fiocchi C: Inflammationinduced endothelial-to-mesenchymal transition: a novel mechanism of intestinal fibrosis. Am J Pathol 2011, 179:2660-2673

21. Flier SN, Tanjore H, Kokkotou EG, Sugimoto H, Zeisberg M, Kalluri R: Identification of epithelial to mesenchymal transition as a novel source of fibroblasts in intestinal fibrosis. J Biol Chem 2010, 285:20202-20212

22. Xu X, Sun S, Xie F, Ma J, Tang J, He S, Bai L: Advanced oxidation protein products induce epithelial-mesenchymal transition of intestinal epithelial cells via a PKC delta-mediated, redox-dependent signaling pathway. Antioxid Redox Signal 2016, 27:37-56

23. Liu $\mathrm{X}, \mathrm{Hu} \mathrm{H}$, Yin JQ: Therapeutic strategies against TGF-beta signaling pathway in hepatic fibrosis. Liver Int 2006, 26:8-22

24. Yata Y, Gotwals P, Koteliansky V, Rockey DC: Dose-dependent inhibition of hepatic fibrosis in mice by a TGF-beta soluble receptor: implications for antifibrotic therapy. Hepatology 2002, 35 : $1022-1030$

25. Southby J, Murphy LM, Martin TJ, Gillespie MT: Cell-specific and regulator-induced promoter usage and messenger ribonucleic acid splicing for parathyroid hormone-related protein. Endocrinology 1996, 137:1349-1357

26. Merryman JI, DeWille JW, Werkmeister JR, Capen CC, Rosol TJ: Effects of transforming growth factor-beta on parathyroid hormonerelated protein production and ribonucleic acid expression by a squamous carcinoma cell line in vitro. Endocrinology 1994, 134: $2424-2430$

27. Kiriyama T, Gillespie M, Glatz JA, Fukumoto S, Moseley JM, Martin TJ: Transforming growth factor beta stimulation of parathyroid hormone-related protein (PTHrP): a paracrine regulator? Mol Cell Endocrinol 1993, 92:55-62

28. Kakonen SM, Selander KS, Chirgwin JM, Yin JJ, Burns S, Rankin WA, Grubbs BG, Dallas M, Cui Y, Guise TA: Transforming growth factor-beta stimulates parathyroid hormone-related protein and osteolytic metastases via Smad and mitogen-activated protein kinase signaling pathways. J Biol Chem 2002, 277:24571-24578

29. McCauley LK, Martin TJ: Twenty-five years of PTHrP progress: from cancer hormone to multifunctional cytokine. J Bone Miner Res 2012, 27:1231-1239

30. Martin TJ, Moseley JM, Gillespie MT: Parathyroid hormone-related protein: biochemistry and molecular biology. Crit Rev Biochem Mol 1991, 26:377-395

31. Wysolmerski JJ: Parathyroid hormone-related protein: an update. J Clin Endocrinol Metab 2012, 97:2947-2956

32. Cheloha RW, Gellman SH, Vilardaga JP, Gardella TJ: PTH receptor1 signalling: mechanistic insights and therapeutic prospects. Nat Rev Endocrinol 2015, 11:712-724

33. Falzon M, Bhatia V: Role of parathyroid hormone-related protein signaling in chronic pancreatitis. Cancers 2015, 7:1091-1108
34. Ardura JA, Berruguete R, Ramila D, Alvarez-Arroyo MV, Esbrit P: Parathyroid hormone-related protein interacts with vascular endothelial growth factor to promote fibrogenesis in the obstructed mouse kidney. Am J Physiol Renal Physiol 2008, 295:F415-F425

35. Ardura JA, Rayego-Mateos S, Ramila D, Ruiz-Ortega M, Esbrit P: Parathyroid hormone-related protein promotes epithelialmesenchymal transition. J Am Soc Nephrol 2010, 21:237-248

36. Liang FF, Liu CP, Li LX, Xue MM, Xie F, Guo Y, Bai L: Activated effects of parathyroid hormone-related protein on human hepatic stellate cells. PLoS One 2013, 8:e76517

37. Ortega A, Ramila D, Ardura JA, Esteban V, Ruiz-Ortega M, Barat A, Gazapo R, Bosch RJ, Esbrit P: Role of parathyroid hormone-related protein in tubulointerstitial apoptosis and fibrosis after folic acidinduced nephrotoxicity. J Am Soc Nephrol 2006, 17:1594-1603

38. Ardura JA, Sanz AB, Ortiz A, Esbrit P: Parathyroid hormone-related protein protects renal tubuloepithelial cells from apoptosis by activating transcription factor Runx2. Kidney Int 2013, 83:825-834

39. Bhatia V, Cao Y, Ko TC, Falzon M: Parathyroid hormone-related protein interacts with the transforming growth factor- $\beta /$ bone morphogenetic protein-2/gremlin signaling pathway to regulate proinflammatory and profibrotic mediators in pancreatic acinar and stellate cells. Pancreas 2016, 45:659-670

40. Bhatia V, Kim SO, Aronson JF, Chao C, Hellmich MR, Falzon M: Role of parathyroid hormone-related protein in the pro-inflammatory and pro-fibrogenic response associated with acute pancreatitis. Regul Pept 2012, 175:49-60

41. Bhatia V, Rastellini C, Han S, Aronson JF, Greeley GH, Falzon M: Acinar cell-specific knockout of the PTHrP gene decreases the proinflammatory and profibrotic responses in pancreatitis. Am J Physiol Gastrointest Liver Physiol 2014, 307:G533-G549

42. Ye Y, Wang C, Du P, Falzon M, Seitz PK, Cooper CW: Overexpression of parathyroid hormone-related protein enhances apoptosis in the rat intestinal cell line, IEC-6. Endocrinology 2001, 142:1906-1914

43. Lezcano V, Gentili C, de Boland AR: Role of PTHrP in human intestinal Caco-2 cell response to oxidative stress. Biochim Biophys Acta 2013, 1833:2834-2843

44. Ahn BY, Saldanha-Gama RF, Rahn JJ, Hao X, Zhang J, Dang NH, Alshehri M, Robbins SM, Senger DL: Glioma invasion mediated by the 75 neurotrophin receptor (p75(NTR)/CD271) requires regulated interaction with PDLIM1. Oncogene 2016, 35:1411-1422

45. Nenquin M, Henquin JC: Sulphonylurea receptor-1, sulphonylureas and amplification of insulin secretion by Epac activation in beta cells. Diabetes Obes Metab 2016, 18:698-701

46. Henquin JC, Nenquin M: Activators of PKA and Epac distinctly influence insulin secretion and cytosolic $\mathrm{Ca} 2+$ in female mouse islets stimulated by glucose and tolbutamide. Endocrinology 2014, 155:3274-3287

47. Shishikura K, Horiuchi T, Sakata N, Trinh DA, Shirakawa R, Kimura T, Asada Y, Horiuchi H: Prostaglandin E2 inhibits neutrophil extracellular trap formation through production of cyclic AMP. Br J Pharmacol 2016, 173:319-331

48. Lawrance IC, Wu F, Leite AZ, Willis J, West GA, Fiocchi C, Chakravarti S: A murine model of chronic inflammation-induced intestinal fibrosis down-regulated by antisense NF-kappa B. Gastroenterology 2003, 125:1750-1761

49. Wirtz S, Popp V, Kindermann M, Gerlach K, Weigmann B, FichtnerFeigl S, Neurath MF: Chemically induced mouse models of acute and chronic intestinal inflammation. Nat Protoc 2017, 12:1295-1309

50. Medina C, Santos-Martinez MJ, Santana A, Paz-Cabrera MC, Johnston MJ, Mourelle M, Salas A, Guarner F: Transforming growth factor-beta type 1 receptor (ALK5) and Smad proteins mediate TIMP1 and collagen synthesis in experimental intestinal fibrosis. J Pathol 2011, 224:461-472

51. Videla S, Vilaseca J, Medina C, Mourelle M, Guarner F, Salas A, Malagelada JR: Selective inhibition of phosphodiesterase-4 ameliorates chronic colitis and prevents intestinal fibrosis. J Pharmacol Exp Ther 2006, 316:940-945 
52. Sellers RS, LeRoy BE, Blomme EA, Tannehill-Gregg S, Corn S, Rosol TJ: Effects of transforming growth factor-beta1 on parathyroid hormone-related protein mRNA expression and protein secretion in canine prostate epithelial, stromal, and carcinoma cells. Prostate 2004, 58:366-373

53. Maycas M, Ardura JA, de Castro LF, Bravo B, Gortazar AR, Esbrit P: Role of the parathyroid hormone type 1 receptor (PTH1R) as a mechanosensor in osteocyte survival. J Bone Miner Res 2015, 30:1231-1244

54. Komori T, Yagi H, Nomura S, Yamaguchi A, Sasaki K, Deguchi K, Shimizu Y, Bronson RT, Gao YH, Inada M, Sato M, Okamoto R: Targeted disruption of Cbfa1 results in a complete lack of bone formation owing to maturational arrest of osteoblasts. Cell 1997, 89:755-764

55. Ducy P, Zhang R, Geoffroy V, Ridall AL, Karsenty G: Osf2/Cbfa1: a transcriptional activator of osteoblast differentiation. Cell 1997, 89: $747-754$

56. Doerks T, Copley RR, Schultz J, Ponting CP, Bork P: Systematic identification of novel protein domain families associated with nuclear functions. Genome Res 2002, 12:47-56
57. Wang BL, Dai CL, Quan JX, Zhu ZF, Zheng F, Zhang HX, Guo SY, Guo G, Zhang JY, Qiu MC: Parathyroid hormone regulates osterix and Runx 2 mRNA expression predominantly through protein kinase A signaling in osteoblast-like cells. J Endocrinol Invest 2006, 29: $101-108$

58. Krishnan V, Moore TL, Ma YL, Helvering LM, Frolik CA, Valasek KM, Ducy P, Geiser AG: Parathyroid hormone bone anabolic action requires Cbfa1/Runx2-dependent signaling. Mol Endocrinol 2003, 17:423-435

59. Saini V, Marengi DA, Barry KJ, Fulzele KS, Heiden E, Liu X, Dedic C, Maeda A, Lotinun S, Baron R, Pajevic PD: Parathyroid hormone (PTH)/PTH-related peptide type 1 receptor (PPR) signaling in osteocytes regulates anabolic and catabolic skeletal responses to PTH. J Biol Chem 2013, 288:20122-20134

60. Weng L, Wang W, Su X, Huang Y, Su L, Liu M, Sun Y, Yang B, Zhou H: The effect of cAMP-PKA activation on TGF-beta1induced profibrotic signaling. Cell Physiol Biochem 2015, 36: $1911-1927$ 